\title{
EMPODERANDO MULHERES COM DOR CRÔNICA PARA LIDAREM COM SEUS SENTIMENTOS POR MEIO DAACUPUNTURA E DO AUTOCUIDADO
}

\author{
Solange Wink ${ }^{1}$, Maria do Horto Fontoura Cartana ${ }^{2}$
}

\begin{abstract}
RESUMO: Teve-se por objetivo nessa pesquisa despertar o poder para o autocuidado em cinco mulheres com queixa de dor crônica há mais de um ano, através de experiências vivenciadas em um processo de cuidar, aliado à aplicação de acupuntura, desenvolvido em encontros de grupo e individuais. O referencial foi fundamentado em Orem, Neves e na Medicina Tradicional Chinesa. A análise de conteúdo dos registros dos encontros e do Diário permitiu identificar a intensidade da dor expressa na Escala Numérica Visual e descrever qualitativamente os sentimentos expressos e a estrutura cognitiva referente à saúde, a qual é indicativa do poder de agenciar o autocuidado. Quatro participantes apresentaram diminuição na intensidade e frequência da dor, avanço no desenvolvimento cognitivo entre o primeiro e o último encontro, remissão das queixas e progressiva suspensão do uso de analgésicos, antidepressivos, laxantes intestinais e indutores de sono.
\end{abstract}

PALAVRAS-CHAVE: Dor; Acupuntura; Autocuidado; Mulheres.

\section{EMPOWERING WOMEN WITH CHRONIC PAIN TO MANAGE THEIR FEELINGS THROUGH ACUPUNCTURE AND SELF CARE}

\begin{abstract}
The aim of the present research was to arouse the self-care energy in clients presenting chronic pain, through experiences lived in a caring process developed individually and in groups. The theoretical-methodological framework was based on Orem, Neves and on the Traditional Chinese Medicine. This work involved the treatment of five women presenting chronic pain for more than one year. The research's data consisted of verbal expressions that were produced in the individual and group living meetings and in the registers in the Diaries. Data analysis aimed to identify the intensity of the pain and to describe qualitatively the expressed feelings and the cognitive structure referring to health, which is an indicator of the client's self-care energy. Four participants referred decreased pain intensity, expressed through the visual numeric scale, between the first and the last meetings.
\end{abstract}

KEYWORDS: Pain; Acupuncture; Self care; Women.

\section{EMPODERANDO MUJERES CON DOLOR CRÓNICO PARA QUE LIDEREN CON SUS SENTIMIENTOS A TRAVÉS DE LAACUPUNTURA Y DELAUTOCUIDADO}

RESUMEN: Se tuvo como objetivo en esta investigación, despertar el poder para el autocuidado en cinco mujeres con queja de dolor crónico a más de un año, a través de experiencias vivenciadas en un proceso de cuidar, aliado a la aplicación de acupuntura, desarrolado en encuentros en grupos e individuales. El referencial fue fundamentado en Orem, Neves y en la Medicina Tradicional China. El análisis de contenido de los registros de los encuentros y del Diario permitió identificar la intensidad del dolor expresado en la Escala Numérica Visual y describir cualitativamente los sentimientos expresados y la estructura cognitiva referente a la salud, la cual es indicativa del poder del cliente de agenciar el autocuidado. Cuatro participantes presentaron disminución en la intensidad y frecuencia del dolor, avance en el desarrollo cognitivo entre el primero y el último encuentro, remisión de las quejas y progresiva suspensión del uso de analgésicos, antidepresivos, laxantes intestinales e inductores de sueño.

PALABRAS CLAVE: Dolor; Acupuntura; Autocuidado; Mujeres.

1Enfermeira. Especialista em Acupuntura. Mestre em Enfermagem. Professora do Curso de Graduação em Enfermagem da Universidade Regional de Blumenau-FURB-SC.

2Doutora em Enfermagem. Professora Adjunto do Departamento de Enfermagem da Universidade Federal de Santa Catarina-UFSC. Membro do Grupo de Pesquisa em Educação.

Autor correspondente:

Solange Wink

Rua 15 de Novembro, 550 - 89010-901 - Blumenau-SC

Recebido: 04/05/09

Email: swink@terra.com.br

Aprovado: 21/08/09

Cogitare Enferm 2009 Jul/Set; 14(3):441-7 


\section{INTRODUÇÃO}

A dor, independentemente da localização no corpo e das causas, continua estimulando os profissionais da saúde a empreenderem estudos com diversas abordagens para seu manejo, visando diminuir o sofrimento das pessoas. Uma destas abordagens, a Medicina Tradicional Chinesa-MTC, define a dor como resultado da obstrução ao livre fluxo de Energia VitalQi pelo corpo ou parte dele. Tal condição está associada a sentimentos bloqueados, não reconhecidos ou não acolhidos $^{(1)}$. Portanto, as possibilidades de superar a dor podem estar associadas ao desvelamento de seu significado, estabelecendo a relação existente entre dor e sentimentos, de maneira a liberar Qi estagnado.

Sendo a dor subjetiva, bem como os sentimentos, somente o portador pode desencadear o movimento de busca de significado, uma ação deliberada que pode ser empreendida a partir de uma visão diferenciada sobre a própria dor ${ }^{(2)}$. Nesse sentido, partindo do pressuposto que é possível estabelecer uma conexão entre o conceito de poder para agenciar o autocuidado ${ }^{(2)}$ e o conceito de $Q i^{(1)}$, uma vez que ambos abordam temas como poder e energia pessoal, escolhas e auto-responsabilidade. A pesquisa foi delineada com o objetivo de despertar nas mulheres o poder de agenciar o autocuidado, para diminuição da intensidade e freqüência da dor crônica, por meio da identificação e verbalização de sentimentos e mobilização do Qi .

\section{FUNDAMENTAÇÃO TEÓRICA}

Visando aproximar as abordagens oriental e ocidental de saúde no cuidado à pessoa com dor, foram empregados os conceitos: de Qi da MTC ${ }^{(1)}$, de demanda terapêutica de autocuidado, poder de agenciar o autocuidado e poder do enfermeiro em agenciar o autocuidado $^{(2)}$, de estrutura cognitiva em saúde ${ }^{(3)}$.

Para sobreviver temos que nos tornar responsáveis pela nossa saúde e escolhas e, à proporção que vamos exercendo a autoresponsabilidade, desenvolve-se a autoridade interna norteadora das condutas e escolhas. Situações emocionalmente dolorosas nos marcam na infância e para não ter que sentir dor a cada vez que ocorra situação similar àquela que nos marcou, escolhemos soluções que naquele momento funcionaram e as repetimos em todas as situações dolorosas que aparecem ao longo do nosso crescimento ${ }^{(4)}$. Uma parte nossa fica atrelada àquela dor e àquela solução, tornando-se uma energia estagnada. No entanto, cada um possui um poder pessoal, o poder de agenciar o autocuidado, que pode ser deliberadamente acionado com a ajuda profissional ${ }^{(2)}$, para enfrentar e resolver a situação.

A demanda terapêutica de autocuidado das participantes era a necessidade de resolver a situação da dor crônica em seus aspectos biológicos (dor física) e psicológico (dor emocional associada aos sentimentos).

O poder de agenciar o autocuidado relaciona-se com o emprego do poder pessoal e a com a capacidade de comprometer-se consigo e escolher assumir o próprio cuidado. O indivíduo que aceita investigar a dor sob uma perspectiva diferenciada, aprende a acolhê-la como uma parte de si mesmo, verifica que esta tem algo de revelador, um ensinamento e um significado a ser desfeito e reconstruído.

Partindo da premissa de que o poder de agenciar o autocuidado, preconizado por Orem ${ }^{(2)}$, relaciona-se com uma das formas de energia vital - $Q i$ - presente em cada ser vivo, portanto um poder pessoal inerente à vida. Entende-se que este poder está disponível para a saúde e bem estar, bastando ser acionado, numa ação deliberada, pelo cliente e pelo enfermeiro. Quando há déficit de autocuidado é o enfermeiro que desempenha o papel de agenciador para suprir a demanda terapêutica.

Quando os dois poderes de agenciar o autocuidado estão juntos, do paciente e do enfermeiro, eles se potencializam e isso possibilita que o cliente agencie o seu autocuidado, sarando a dor. Esta atitude libera a falsa crença de cura segundo o modelo biomédico, no qual a responsabilidade é deslocada para uma autoridade externa. O peso de cuidar do outro é suavizado, uma vez que o cliente e a enfermeira fazem cada um a sua parte e assumem a sua própria responsabilidade no processo de sarar.

Há dois aspectos de Qi relevantes para a MTC $^{(5)}$ : a) ele se manifesta simultaneamente em nível físico (Yin) e em nível mental, espiritual (Yang); b) está em constante movimento de agregação (Yin) e de dispersão (Yang). Isso explica a forma integrativa da MTC, na qual mente, corpo e energia são indissociáveis, interdependentes, representando diferentes graus de condensação do Qi. Também explica o fato de um sentimento como a raiva, por exemplo, poder causar danos físicos. O sentimento é uma forma de $Q i$, se apresentando numa forma diversa de agregação de partículas. O sentimento estagnado por longo tempo, perturba o livre fluxo do Qi pelo organismo, podendo 
levar a dor, distensões, massas ou depressão( ${ }^{(5)}$. Por outro lado, o mau funcionamento orgânico pode se traduzir em estados de espírito desarmônicos.

A movimentação correta do Qi no organismo é fundamental para a fisiologia corporal e para a saúde. Cada órgão tem um efeito particular sobre o Qi da mesma forma que cada sentimento tem um efeito particular sobre ele e, consequentemente, sobre o órgão ${ }^{(5)}$. Por outro lado, se o autocuidado for efetivo, contribuirá para a integridade estrutural, funções e desenvolvimento humano ${ }^{(2)}$.

Dentro desse mesmo raciocínio, acreditamos que o enfermeiro que exerce o próprio poder para despertar no outro o autocuidado está mobilizando a sua energia vital. E, ao mobilizar este poder em si e no outro, ele contribui para que o cliente comece a perceber e a acreditar no próprio poder, iniciando um processo de libertação da autoridade externa. Essa modificação concretiza-se e é revelada na forma do cliente se expressar, na estrutura semântica de sua expressão verbal e escrita e no enfrentamento da dor.

O desenvolvimento ético e intelectual segue um padrão de organização através do qual o indivíduo constrói suas experiências, especialmente as relativas à natureza e origem do conhecimento, valores e responsabilidades ${ }^{(4)}$. Estes padrões são apresentados como: dualismo, relativismo e comprometimento no relativismo ${ }^{(3-4)}$. Cada padrão é caracterizado por três posições, totalizando nove formas de perceber o mundo, registradas nas seguintes expressões ${ }^{(4)}$ : estrutura semântica - uso de absolutos; autoprocessamento; análise; abertura para alternativas; habilidade de assumir responsabilidade; habilidade de assumir novos papéis; localização do controle interno; síntese; habilidade de assumir riscos consigo mesmo.

O desenvolvimento e crescimento pessoal evolui do dualismo para o relativismo e, deste, para o comprometimento no relativismo, numa forma qualitativamente crescente e complexa, atrelada ao modo de pensar sobre assuntos que dizem respeito à vida da pessoa ${ }^{(4)}$.

Os clientes identificados como dualistas e que permanecem nesta categoria, bem como os que não evoluem qualitativamente de dualistas a relativistas não agenciam seu autocuidado(3) na integralidade. Portanto, não mobilizam o seu Qi para as mudanças e melhorias do quadro álgico.

A partir da observação da estrutura cognitiva do cliente, pode-se, durante o prosseguimento do processo de cuidar, verificar se ocorrem mudanças nas expressões utilizadas pelo cliente e/ou na localização de controle, o que permite perceber se o cliente começa a apropriar-se de suas questões. Entretanto, o indivíduo pode não apresentar evolução na sua estrutura cognitiva ao escolher alternativas como: manter-se apegado ao problema, considerar a mudança exagerada para sua capacidade, ressentirse com a situação, mostrar-se alienado ou necessitar de mais tempo ${ }^{(4)}$.

\section{METODOLOGIA}

É uma pesquisa de natureza qualitativodescritiva $^{(6)}$. Foi desenvolvida com cinco mulheres com queixa de dor crônica há mais de um ano. Os critérios de inclusão foram o tempo de dor, idade acima de 21 anos, se comprometer em fazer um diário de dor e aceitar participar de uma pesquisa com abordagem diversa da do tratamento que vinham mantendo. Os dados foram coletados por cinco meses, de junho a outubro de 2005 a partir: dos Diários pessoais; encontros grupais semanais (num total de 16 encontros com uma hora e meia de duração); encontros individuais e sessões de acupuntura (16 a 27 sessões); registros pessoais durante o processo de cuidar. Os encontros ocorreram em uma clínica na cidade de Blumenau-SC, com Alvará Sanitário vigente.

Como método para obtenção dos dados exerceu-se o poder do enfermeiro em agenciar o autocuidado, empregando uma tecnologia de cuidado e investigando os sentimentos do cliente sem necessidade de interpretá-los. Esta tecnologia, que utilizou também a focalização, o Diário e a acupuntura, favorece a autodescoberta dos fatores desencadeadores de dor para suprir a demanda terapêutica, estimular o desenvolvimento cognitivo e mobilizar o poder para o autocuidado.

Focalização (Focusing) ${ }^{(7-8)}$ é uma habilidade que favorece a autopercepção ao focar uma sensação corporal (felt sense), como se fosse uma forma de ouvir o corpo e não a mente, a partir de uma situação que remeta a algo desagradável, por exemplo, a dor. Os passos desse processo são: 1. Abrindo/Criando um espaço; 2. Sensação sentida; 3. Enfrentando; 4. Ressoando; 5. Perguntando; 6. Acolhendo. Os passos não são necessariamente seguidos obedecendo a essa ordem, não se apresentam sempre da mesma forma para todas as pessoas, nem para o mesmo indivíduo. O próprio desenrolar da focalização é o norteador do processo de autopercepção. Com o treinamento da 
habilidade de focalização, o cliente vai aprofundando o conhecimento de seu mundo interno o que o ajuda a compreender a si mesmo e aos outros, no contexto em que ele se desenvolveu e/ou agora vive, além das características da sua dor.

O Diário consiste no registro dos dados objetivos de mensuração de dor: datas, horários, intensidade, freqüência, localização, analgésico e dose empregada. O encontro consigo proporcionado pelo Diário pode ser uma forma de despertar a energia pessoal, já que o pensamento conduz a energia ${ }^{(5)}$, desvelando o potencial adormecido, ajudando-o a iniciar o agenciamento do autocuidado como uma ação deliberada ${ }^{(2)}$.

A acupuntura, uma das formas alternativas recomendadas para tratamento de dores crônicas, foi realizada em encontros individuais na forma de crânioacupuntura de Yamamoto $^{(9)}$ e auriculoterapia ${ }^{(10)}$.

O projeto seguiu as formalidades éticas legais e foi autorizado pelo Comitê de Ética da Fundação Universidade Regional de Blumenau sob n ${ }^{\circ}$ 012/05 e todas as participantes mantiveram o uso de medicamentos a que estavam habituadas, até considerarem, livremente e com aval médico, não ser mais necessário. Cada participante escolheu seu codinome.

O procedimento de análise dos dados foi fundamentado na análise de conteúdo temática ${ }^{(12)} \mathrm{com}$ os temas: intensidade de dor; sentimentos expressos e evolução dos padrões da estrutura cognitiva.

\section{COMPREENDENDO E EMPODERANDO AS PARTICIPANTES}

As cinco mulheres tinham entre 40 e 50 anos de idade, eram casadas, quatro possuíam filhos, uma netos. Todas realizavam trabalho doméstico, além do profissional remunerado; residiam em casa própria e possuíam automóvel. Dentre elas, quatro apresentavam diagnóstico médico de fibromialgia, com um caminho percorrido de tratamento de dor já estabelecido há mais de um ano. Uma participante apresentava dores em várias localizações do corpo. Todas inicialmente apresentavam queixas semelhantes: quadro depressivo como tristeza e desânimo, insônia, distúrbios emocionais, falta de ânimo, cansaço, mau humor, conflitos de relacionamento com familiares, localização e intensidade de dor.

Os dados iniciais evidenciaram muito sofrimento na história pessoal de busca de solução para a dor. $\mathrm{O}$ caminho percorrido anteriormente a pesquisa havia se mostrado ineficaz e longo, com custos elevados, pessoais e públicos, despendidos em consultas com vários profissionais, exames, procedimentos invasivos de risco e potencialmente danosos, além das dificuldades e esforço para cumprir tarefas rotineiras. Porém, todas mantiveram, nesta trajetória, o desejo de mostrar ao mundo que não exageraram nem supervalorizaram suas dores e que tinham o direito de serem compreendidas na sua dor de alma.

Dentre as cinco participantes quatro apresentaram diminuição da dor à medida que evoluiu o processo de cuidar. Uma delas não apresentou qualquer alteração ao final da pesquisa, registrando o valor 10 na Escala Numérica Visual em que 10 significa “a pior dor imaginável” e 0 “nenhuma dor”. Dentre as quatro participantes que apresentaram diminuição da dor, ao início da pesquisa, três atribuíram 10 à intensidade da dor e, destas, duas, ao final, atribuíram 0 na escala significando nenhuma dor e uma 2 significando dor leve. Uma outra participante atribuiu o valor 6 à dor inicial e 2 à final. Todas as quatro deixaram de fazer uso de analgésico, medicação antidepressiva e uma suspendeu, com aval médico, toda a medicação que vinha tomando.

À medida em que ocorria o processo de cuidar e principalmente a prática da habilidade de focalização, os sentimentos e sensações negativas sentidas foram aflorando. Os sentimentos desagradáveis foram percebidos com mais freqüência no início do processo e foram dando lugar a sentimentos agradáveis. Os sentimentos inicialmente manifestos foram o de medo (29 vezes) seguido por solidão (15 vezes). Conforme a $\mathrm{MTC}^{(5)}$, se categorizarmos como raiva os sentimentos expressos como mágoa (12), raiva (7), ressentimento (2), frustração (5) e irritação (3) totalizamos 29 ocorrências.

Conforme MTC ${ }^{(5)}$, o medo afeta os rins, os quais: a) são a raiz do Yin e do Yang e comandam os ossos, além de todas as funções de transporte de líquidos corporais e transformação no corpo; b) armazenam a vontade Zhi, que é uma das cinco manifestações do Shen, espírito ou mente, determinação e força de vontade, um Yang Qi do Rim ${ }^{(5,11)}$. Um Rim amedrontado, não consegue cumprir suas funções e a vontade é fraca ${ }^{(5)}$. A raiva é relativa ao Fígado, o qual controla os tendões, ligamentos, cartilagens e também responde pelo fluxo harmonioso do Qi pelo corpo $^{(5)} \mathrm{e}$ pelo fluxo suave e uniforme dos sentimentos. Outra função do Fígado é o de armazenar o Sangue e quando o Qi não circula livremente, compromete a circulação 
de Sangue e a nutrição do corpo ${ }^{(5,11)}$. Havendo raiva, um sentimento que faz o Qi subir num Fígado, que por sua natureza Yang tende ao excesso, ocorre excessos na parte alta do corpo que se traduzem em dores de cabeça, ombros tensos, irritabilidade, rompantes de raiva, insônia, tensões. Estas manifestações, em geral, acabam impedindo o fluxo livre de energia vital pelo corpo e os tendões e ligamentos ficam mal nutridos, agravando o quadro e se traduzindo no cansaço tão presente nos relatos das participantes.

Quando a raiva é reconhecida, este $Q i$ estagnado tem possibilidade de ser movimentado. A consciência dos sentimentos libera o Qi e a pessoa pode autoprocessar esta percepção, deixando de considerar o outro como responsável pela geração da sua raiva e prosseguindo na análise de sua situação. Isso possibilita à pessoa exercer a liberdade de escolher permanecer como está ou permitir-se assumir novos papéis e correr riscos. "O Fígado é o general do palácio, elabora planos e táticas”(11:66), se desarmônico é incapaz de planejar ou de analisar, o que faz com que a pessoa permaneça atrelada ao controle externo e não evolua para formas mais complexas de pensar e resolver seus assuntos.

Sentimentos agradáveis, expressos pelas participantes durante o processo de cuidar, incluíram: bem estar (14), felicidade (13), amor por si e pelos outros (10), coragem, respeito, prazer e paz. A sensação de bem estar foi frequentemente mencionada no transcurso da melhora no quadro álgico e mudança qualitativa na estrutura cognitiva.

As expressões de força, respeito a si própria, coragem, decisão fortalecida, exercer a vontade, firmeza, poder, confiança, determinação e valor foram considerados como indicativos de agenciamento do poder para o autocuidado e se tornaram mais presentes à medida que a pesquisa evoluiu, concomitantemente com manifestações de melhora na intensidade e freqüência de dor. É interessante notar que na participante que não apresentou melhora no seu quadro álgico estas expressões aparecem uma única vez, mostrando a falta de aptidão para o autocuidado, evidenciando a sua escolha em permanecer na situação, ou falta de estrutura cognitiva mais complexa que lhe permitisse analisar a situação, enfrentar e fazer as escolhas diferentes.

Quatro participantes ao início da pesquisa apresentaram expressões verbais e escritas condizentes com os indicadores da categoria de estrutura cognitiva Dualismo e uma correspondente ao início do Relativismo. Das quatro dualistas uma se manteve nesta categoria (a que se manteve com dor), três moveram-se para a categoria de Relativismo e uma participante evoluiu qualitativamente dentro desta última categoria.

As mulheres dualistas se percebiam como dependentes do profissional de saúde, encarregado-o de resolver sua dor. Não satisfeitas e sem resultados, mudavam frequentemente de profissional ou de forma de tratamento. Ao iniciarem a participação nesta pesquisa, todas relataram que consultavam médicos, massagistas, acupunturista e Centro Espírita. Não tinham ainda o entendimento de que estavam depositando sua confiança em uma autoridade externa que lhes ofereceria uma solução para tratar ou fugir da dor. Como referiu uma das participantes:

Não sabia se a solução seria obtida em um SPA ou se em uma viagem para tentar distrair-me (E).

Não analisavam e não questionavam a falta de alcance do resultado esperado para alívio da dor; apenas mudavam de abordagem e continuavam procurando uma solução mágica:

\section{[...] eu fui a todo lugar que disseram para mim que pudesse obter alguma ajuda (B.1).}

[...] acordei com a esperança de que hoje "algo" vai me direcionar para o caminho certo, [...] mas acho que ao final do dia fico frustrada por continuar paralisada (B.D).

\section{[...] gostaria de estalar os dedos e resolver tudo [...] (E.1).}

A busca dos dualistas pode ser vista como um movimento pessoal para obter resultados efetivos. No entanto, o que ocorre é uma estagnação; as pessoas dualistas tornam-se autoridades na sua dor, descrevemna com detalhes. O dia-a-dia é determinado pela dor, uma autoridade evidente e manifesta que não é do Ser, mas de uma parte sua não consciente. Isso fala de um Qi estagnado, materializado em dor física.

As participantes que evoluíram para o Relativismo passaram a questionar seus hábitos e crenças, suas posições na família, seus afazeres, analisaram e vislumbraram novas formas de ver a dor e passaram a identificar a relação existente entre dor física e sentimento. Voltaram a ter confiança em si 
mesmas e iniciaram um processo de auto- descoberta:

[...] É estar feliz comigo mesma, com o que estou produzindo. E que esta felicidade não está fora de mim e sim dentro de mim. E é olhando dentro de mim que vou conseguir encontrá-la e vivenciá-la, seja de que forma for [...] (B.D).

[...] estou caminhando sozinha, ou melhor, caminho "comigo mesma" porque me encontrei. Caminho devagar, porém com firmeza. Sei que posso melhorar ainda mais, mas já sei como tratar comigo mesma. Já sei que meus pensamentos geram as minhas emoções e se souber administrá-los e direcioná-los bem, estarei melhor todos os dias. Hoje sei o que é olhar para mim e gostar do que vejo (E.16 R).

[...] As outras vezes quando nós discutíamos [eu e meu marido] eu ficava assim, não falava o que eu queria e ficava quieta [...] aquele dia eu tive coragem e briguei mesmo [...]. Eu tinha dor, dor de cabeça, dor nas pernas, dor nos braços, dor na coluna, era dor por todo o corpo, uma dor estranha mesmo e quando acontecia uma coisa assim que eu ficava assim irritada ou tinha ódio [...]. (M. 4).

As participantes apresentavam, inicialmente, pouca abertura para alternativas e não assumiam riscos. À medida que a focalização e o hábito de reflexão e de sentir o sentimento e não apenas descrevê-lo foi sendo incorporado por cada uma, percebe-se o quanto essa forma de se conhecer exige um arriscar-se, uma abertura para alternativas.

As nove áreas ou mudanças qualitativas na forma de perceber o mundo permitiram avaliar a evolução em direção ao autocuidado e a concomitante remissão da dor, a mudança na qualidade dos sentimentos expressos e o reconhecimento de um poder pessoal interno. A capacidade de análise foi identificada como sendo o ponto de mutação. A partir deste ponto, a capacidade de assumir responsabilidades se ampliou, as participantes passaram a se responsabilizar pela própria saúde e bem estar, a arriscar-se em novas regras de comportamento frente aos problemas e o locus de controle passou a ser interno. Com isso ocorreu a síntese, a compreensão dos sentimentos potencialmente dolorosos e a dependência para ser saudável e feliz deixou de ser externa. As participantes passaram a exercer a habilidade de arriscar-se a partir de uma confiança interna e do poder pessoal e tiveram a melhora do quadro álgico, como um todo.

O exercício conjunto dos poderes das participantes e da enfermeira trouxeram à consciência os sentimentos guardados interiormente e não expressos, o que deu significado à integralidade da dor, perdendo o potencial de causar dor física, liberando a energia estagnada e restabelecendo o fluxo energético. Essa constatação se relaciona ao movimento do autocuidado ${ }^{(2)}$ e à visão chinesa de mundo em contínuo estado de mudança ${ }^{(5)}$.

As categorias que se referem ao poder do enfermeiro em agenciar o autocuidado ${ }^{(13)}$ foram: (a) protegendo os direitos das participantes; (b) integrando, buscando e agradecendo a proteção espiritual; (c) estimulando o poder de agenciamento de autocuidado; (d) implementando tecnologia de cuidado e (e) avaliando o desenvolvimento do poder da(o) enfermeira(o) de agenciar o autocuidado.

\section{CONSIDERAÇÕES FINAIS}

Para que a ação de cuidar ocorra, estabelece-se uma relação interpessoal na qual os que necessitam de atenção se comunicam e mantém contato com os que proveem cuidados. Esse contato presume legitimidade nas posições de cada um, bem como responsabilidade e vontade de estabelecer um acordo prévio sobre o que será feito, podendo resultar na mútua aceitação da relação ou na decisão de uma das partes escolher se retirar por razões pessoais ou profissionais. Se a escolha pela continuação da relação de cuidado persistir há uma demanda de contínua comunicação que é afetada por atitudes, crenças, valores, maturidade e pelo estado de saúde dos indivíduos envolvidos na relação.

A comunicação necessita: que o profissional seja experiente, conhecendo seu campo de atuação de uma forma estável e consistente, e que seja também capaz de aplicar seu conhecimento de uma forma prática e crítica; que o profissional de enfermagem tenha conhecimento específico, pois um prestador de serviço de saúde deve ser prático, sendo capaz de mover-se de um insight sobre uma condição humana ou ambiental, que deva ser regulada ou controlada, para uma tomada de decisão e engajamento na ação para obter os resultados desejados; que haja legitimidade na relação interpessoal entre cliente e profissional para validação do contrato social estabelecido, de forma a promover a efetividade no desenvolvimento do sistema de comunicação. Tais saberes tornam-se mais efetivos 
quando o provedor de cuidado possui conhecimentos sobre si mesmo como pessoa, possui disposição e se compromete a ajudar o outro no processo, pois sabe que esse é um caminho que possibilita resultados efetivos.

\section{REFERÊNCIAS}

1. Maciocia G. The practice of chinese medicine. The treatment of disease with acupuncture and chinese herbs. Edinburgh: Churchill Livingstone; 1994.

2. Orem DE. Nursing - concepts of practice. 6th ed. St Louis: Mosby Inc; 2001.

3. Neves EP. The relationship of hospitalized individuals cognitive structure regarding health to their health selfcare behaviors [tese]. Washington DC (USA): School of Nursing of the Catholic University of America; 1980.

4. Perry WG. Forms of intellectual and ethical development. New York: Holt, Rinehart and Winston; 1970.

5. Maciocia G. The foundations of chinese medicine: a comprehensive text for acupuncturist and herbalists. Edinburgh: Churchill Livingstone; 1989.

6. Neves-Arruda E, Zagonel IPS. Pesquisa-cuidado: uma abordagem metodológica que integra pesquisa, teoria e prática em enfermagem. Cogitare Enferm. 2006; 11(1):73-9.

7. Gendlin E. Focusing. USA: Bantam Books; 1981.

8. Cornell A W. The power of focusing. A practical guide to emotional self-healing. Oakland: New Harbinger Publications; 1996.

9. Yamamoto T. New scalp acupunture. Japan: Axel Springer Japan Publishing Inc; 1998.

10. Yamamura Y. Acupuntura tradicional. a arte de inserir. São Paulo: Roca; 2004.

11. He e Ne. Teoria básica de medicina tradicional chinesa. São Paulo: Atheneu; 1999.

12. Hsiu-Fang Hsieh, Shannon SE. Three approaches to qualitative content analysis. Qualitative Health Research, 2005;15:1277.

13. Wink S. Um processo de despertar o poder para o autocuidado em clientes com dor crônica na perspectiva oriental de saúde: uma pesquisa cuidado em enfermagem [dissertação]. Florianópolis (SC): Universidade Federal de Santa Catarina; 2005. 